\title{
Suiformes orthologous satellite DNAs as a hallmark of Pecari tajacu and Tayassu pecari (Tayassuidae) evolutionary rearrangements
}

\author{
Filomena Adega*, Raquel Chaves, Henrique Guedes-Pinto
}

Institute for Biotechnology and Bioengineering, Centre of Genetics and Biotechnology, University of Trás-os-Montesand Alto Douro (IBB/CGB-UTAD), Apdo 1013, 5001-801 Vila Real, Portugal

\section{Keywords:}

Orthologous

satellite DNA

Suidae

Tayassuidae

Evolutionary breakpoints

\begin{abstract}
A B S T R A C T
In a broad general way, eukaryotic satellite DNA sequences are characterized by a highly dynamic molecular behavior due to concerted evolution that leads to rapid change between repeat sequences of different species, achieved by amplification of new variants during speciation or by gradual sequence evolution due to the accumulation of nucleotide substitutions. There are, although exceptions for this almost universal rule. We isolated variants from both the Mc1 and Ac2 pig (Sus scrofa, Suidae) satellite DNA families from the genomes of two Tayassuidae members: Pecari tajacu and Tayassu pecari, which have highly derived karyotypes. The presence of these sequences in both families' genomes (Suidae and Tayassuidae) implies their existence in a common ancestor, what confers to the variants the status of orthology and the approximate age of, at least 40 million years.

While at the molecular composition level these orthologous sequences are highly homologous, crossspecies physical mapping revealed a completely different chromosomal location in Suidae versus Tayassuidae families, most probably, reflecting the high level of divergence and chromosomes evolution pathways after radiation of each family. Detailed comparative analysis of the satellites assignment on the peccary's chromosomes revealed its co-localization with homologous evolutionary breakpoints in both species, suggesting their involvement in the rearrangement events. The complex behavior of the repeats evolution in the pig/peccaries genomes is here clearly illustrated. These sequences are molecularly preserved for a considerable period of time and display slow rates of sequence change, but show a dynamic motion behavior throughout the peccary's genomes that accompanied the great architectonic reorganization of Tayassuidae chromosomes during evolution.
\end{abstract}

\section{Introduction}

The genomes of higher eukaryotes harbour great amounts of various types of repeated sequences. According to their organization, two major classes, interspersed and tandem repeats can be distinguished. Satellite DNAs consist of long tandem arrays of more or less well-defined repeat units and except mammal neocentromeres (Kereso et al., 1996; Barry et al., 1999), all higher eukaryotic centromeres examined so far have been found to consist of families of these highly repeated sequences (Tyler-Smith and Willard, 1993; Ekes et al., 2004).

High-resolution mapping of the pericentromeric region of eukaryotic chromosomes will help to understand the significance of noncoding DNA, a subject in focus, now that the genome drafts have shown the important link between these sequences and the function of genome components (Cawley et al., 2004; Kuznetsova et al., 2005).

* Corresponding author. Tel.: +351259350 841; fax: +351259350 572 E-mail address: filadega@utad.pt (F. Adega).
Sus scrofa has a bimodal karyotype with two autosomal subsets of 12 meta-/submetacentric (Mc) and 6 acrocentric (Ac) chromosome types, the Mc and Ac "subgenomes" and the centromeric heterochromatin is characterized by two distinct satellite DNA families designed $\mathrm{Mc1}$ and Ac2 (Jantsch et al., 1990). The Mc1 satellite family is located at the centromeric region of the metacentric chromosomes of pig (SSC1-12) and in the $\mathrm{X}$ chromosome, and their centromeres have been shown to be composed of divergent $340 \mathrm{bp}$ monomer units (Jantsch et al., 1990; Miller et al., 1993; Rogel-Gaillard et al., 1997). Jantsch et al. (1990) observed a high degree of diversity in the Mc1 satellite family, with some satellite members being chromosome-specific. The Ac2 family is found in the acrocentric chromosomes (SSC13-18), and is a homogeneous satellite occurring at the subterminal pericentromeric regions of all Ac autosomes being their centromeres comprised by $14 \mathrm{bp}$ monomer units. 
The primed in situ (PRINS) labeling technique, with primers derived from the Ac2 and Mc1 DNA families has been used to label the centromeres of several subgroups of swine chromosomes, and represents a tool for identifying regions containing repetitive DNA in swine (Rogel-Gaillard et al., 1997). A number of additional satellite DNA repeats have been isolated from pig genomic DNA (Janzen et al., 1999; Milleret al., 1993; Riquet et al., 1996).

Peccaries belong to the Cetartiodactyla family Tayassuidae and are New World relatives of the Old World true pigs (family Suidae). There are three recognized extant peccary species, all confined to the American continent; the white-lipped peccary (Tayassu pecari), the collared peccary (Pecari tajacu) and the chacoan peccary (Catagonus wagneri) (Groves and Grubb, 1993). Pigs and peccaries diverged something like 40 million years ago (Mya), and since then their karyotypes underwent complex rearrangements as fusions/ fissions, inversions and tandem translocations that difficult the virtual reconstruction of one karyotype into another (Bosma et al., 2004; Adega et al., 2006b).

Besides the regulatory and architectural roles mentioned by Venter et al. (2001), the genome repetitive sequences are valuable markers of chromosomal evolution (Lander et al., 2001). The existence of a whole range of satellite sequences, either conserved or diverged, gives the opportunity to understand the evolutionary history, chromosome structure and the dynamic changes of satellite DNA and chromosomes evolution (Ugarkovic and Ploh1, 2002) allowing the exploitation of the data to make inferences about phylogeny.

Here we investigated variant members (specifically, the AC1 and CE2 variants) of the two pig major satellite DNA families (Ac2 and Mc1) in the two Tayassuidae genomes, P. tajacu and T. pecari. Our findings allowed great resolution of the phylogenetic history of these satellite DNA families and therefore the chromosomal evolutionary pathways of the species in analysis.

\section{Materials and methods}

\subsection{DNA extraction, amplification and sequencing}

Genomic DNA from the species analyzed: P. tajacu (PTA, collared peccary), S. scrofa (SSC, domestic pig) and T. pecari (TPE, white-lipped peccary) was isolated from peripheral blood using standard methods (Montgomery and Sise, 1990).

PCR specific primers for the AC1 and CE2 satellite DNA sequence variants from the Ac2 family and Mc1 family respectively, from domestic pig were used following Rogel-Gaillard et al. (1997), specifically:

AC1 $5^{0}$-TCGGATGGCTTTGGGCG-3 ${ }^{0}$ and

CE2 $5^{0}$-TGTGTTTCCCAGGCCCCAT- $3^{0}$.

to amplify these satellite DNA families from the genome of the three species in analysis. Amplification of genomic DNA originated fragments from each of the species; PCR products were cloned into a pZero2.1 plasmid (Invitrogen, Life Technologies) and sequenced. Each clone was used as probe for FISH experiments.

DNA sequences were analyzed using BLASTN searches of the Genbank and EMBL databases to confirm the sequences identity. Sequence data from the clones will be deposited in the EMBL Nucleotide Sequence Database accession after complete analysis.

\subsection{In situ hybridization}

Chromosome preparations of each of the species analyzed were made from short-term lymphocyte cultures of whole blood samples using standard protocols (Chaves et al., 2002). The nomenclature for domestic pig chromosomes $(2 \mathrm{n}=38)$ is that of the Committee for the Standardized Karyotype of the Domestic Pig (1988).

The karyotype of $\mathrm{T}$. pecari (individuals from South America) consists of 26 chromosomes, being the two largest chromosome pairs submetacentric, nine pairs metacentric/submetacentric, the smallest autosomal pair acrocentric, the sex chromosome $\mathrm{X}$ a medium acrocentric, and the $\mathrm{Y}$ a small acrocentric.

The P. tajacu karyotype here analyzed is characterized by a diploid chromosome number of 30 , being eight autosomal pairs metacentric/submetacentric, six autosomal chromosome pairs acrocentric, the sex chromosome $\mathrm{X}$ a medium submetacentric, and the $\mathrm{Y}$ a small acrocentric. The nomenclature used for the chromosomes of T. pecari is that of Bosmaet al. (2004) and P. tajacu is that of Adegaet al. (2006b).

Air dried slides were treated at $658 \mathrm{C}$ for $6 \mathrm{~h}$ and then submitted to in situ restriction endonuclease digestion with ApaI and fixed with paraformaldehyde as described by Chaves et al. (2002). Slides were stained with DAPI (the inversion of the DAPI color enhanced the RE-banding helpful for chromosome identification) and then used for in situ hybridization experiments.

Metaphases were hybridized in situ with the satellite clones labeled with digoxigenin-11-dUTP (Roche) or biotin16-dUTP (Sigma) by PCR using standard methods (Schwarzacher and Heslop-Harrsion, 2000; Chaves et al., 2003). Hybridization was carried out in 2 SSC and $50 \%$ formamide at $378 \mathrm{C}$ overnight, and the most stringent post-hybridization wash was in 0.2 SSC at $428 \mathrm{C}$, allowing sequences with more than $82 \%$ similarity to remain hybridized.

Digoxigenin-labeled probes were detected with anti-digoxigenin (Roche) conjugated to 5-carboxy-tetramethylrhodamine (5TAMRA) and Biotin-labeled probes were detected with avidin conjugated to fluorescein isothiocyanate (FITC) (Vector Laboratories). Chromosomes were counterstained with DAPI and mounted in Vectashield (Vector Laboratories). Chromosome preparations were analyzed with a Zeiss Axioplan 2 Imaging microscope coupled to an Axiocam digital camera and with the AxioVision software (Version 3.1). Digitized photos were prepared for printing in Adobe Photoshop (Version 5.0); contrast, overlaying and color optimization functions were used and all affected the whole of the image equally.

\section{Results}

\subsection{Satellite DNA sequences in Suidae/Tayassuidae}

Amplification of genomic DNA with primers for pig satellite DNA families (AC1 and CE2, respectively) in species from the Suidae and Tayassuidae gave rise to PCR fragments with lengths of approximately $400 \mathrm{bp}$ (for $\mathrm{AC} 1$ ) and $1 \mathrm{~kb}$ (for $\mathrm{CE} 2$ ), and one fragment from each satellite family variant and species was cloned. In a few cases, where more than one fragment was amplified, the 
$400 \mathrm{bp}$ (AC1) and the $1 \mathrm{~kb}$ (CE2) (preferentially amplified fragments-stronger bands in the agarose gel) amplification fragments were selected for reamplification and cloning. All clones showed homology to the Ac2 or Mc1 satellite DNA families (EMBL accession X51563 and X51555, for instance). The different clones showed between 83 and $86 \%$ similarity among each other (for each of the satellite DNA families analyzed) and among reference sequences.

3.2. Cross-species and cross-families analysis of the satellite DNA families

The different satellite sequences showed the expected centromeric localization in the domestic pig chromosomes, so there was sufficient homology that the $\mathrm{AC} 1$ and $\mathrm{CE} 2$ from the different species hybridized to the pig genome. In Fig. 1 it is possible to observe representative in situ hybridizations of the different clones on metaphase pig chromosomes, namely AC1SSC, AC1PTA and AC1TPE (Fig. 1a-c, respectively) and CE2SSC, CE2PTA and CE2TPE (Fig. 1d-f, respectively).

$\mathrm{AC} 1$ sequence isolated from the pig genome labels all the centromeres of its acrocentric chromosomes (Fig. 1a) SSC13-18 heterogeneously, namely, chromosomes SSC13 is the chromosome presenting the less intensity signal and chromosomes SSC16-18 show the brighter hybridization signals. These observations are suggestive of the existence of different amounts of the sequences throughout these acrocentric autosomes. A submetacentric autosome, chromosome SSC6 also revealed the presence of this satellite family at its centromere and chromosome SSC7 at one chromosome pair. Similar results were observed when analyzing the hybridization results of the isolated AC1 sequences from the genome of $\mathrm{P}$. tajacu on the S. scrofa chromosomes (Fig. 1b), except for the submetacentric chromosomes SSC6-7, that showed a faint hybridization signal. Finally, the AC1 related sequence isolated from T. Pecari (Fig. 1c) gave rise in pig chromosomes to slightly different results, specifically, this probe labeled more autosomes centromeres (arrows) than the previous ones, moreover the hybridization signal seems to be stronger.

CE2 sequence isolated from S. scrofa (Fig. 1d) labels the majority but not all the metacentric chromosomes of pig, heterogeneously. Chromosome SSC1 is the autosome presenting the strongest hybridization signal, and five metacentric autosomes apparently lack hybridization signal (SSC4, SSC5, SSC8, SSC10 and SSC11). The in situ hybridization results with CE2PTA (Fig. 1e) were very similar with those observed with the homologous pig sequence and there can be observed three metacentric autosome pairs (SSC5, SSC10 and SSC11) apparently lacking satellite DNA. Finally, as observed for the AC1 satellite, the CE2TPE (Fig. 1f) hybridization results were slightly different from the ones obtained with the other two species sequence variants. Although chromosomes SSC4, SSC10 and SSC11 did not present detectable hybridization signal, as in the other two species sequences, chromosomes SSC13 and SSC17 (acrocentric) present a considerable amount of satellite DNA at the centromeres (arrows).

Satellite DNA polymorphisms were observed between homologous chromosomes in the different sequences hybridizations.

$\mathrm{AC} 1$ and $\mathrm{CE} 2$ sequences from the different species were then in situ hybridized to metaphase chromosomes of $\mathrm{P}$. tajacu and $\mathrm{T}$. pecari. Interestingly the satellite signals are specifically distributed at multiple chromosome regions. This distribution and heterogeneous pattern can be observed in the majority of the peccary's chromosomes of the two species, with a few chromosomes lacking hybridization signal, at least apparently. To a clear illustration of these results, haploid karyotypes were constructed, and some representative ones can be seen in Fig. 2; specifically, P. tajacu chromosomes hybridized with AC1TPE (Fig. 2a) and CE2PTA (Fig. 2c), and TPE with AC1SSC (Fig. 2b). The in situ hybridization results are shown in the left side of each chromosome (after DAPI inversion, to a better signals localization). Also C-bands are indicated with arrows. The two different satellite hybridizations form in the $P$. tajacu chromosomes large blocks in some chromosomes, see as examples, PTA2, PTA3 and PTA10 with both satellites (Fig. 2), PTA4 and PTA9 with AC1 (Fig. 2). Some chromosomes, however, seem to lack hybridization signal or the signal is too diffuse or faint, like PTA5 and PTA13 with AC1 satellites. PTAX chromosome shows the presence of both satellite DNA families, at different locations, $\mathrm{AC} 1$ in the long arm and CE2 mainly at the centromere.

In $\mathrm{T}$. pecari, the satellite sequence here presented is also heterogeneously distributed through the majority of the chromosomes (Fig. 2), with some chromosomes displaying large blocks of satellite, as TPE1, TPE2, TPE3, TPE4 and TPE11, and other chromosomes, as TPE10, TPE12 with a very faint hybridization signal and the $\mathrm{Y}$ chromosome (Fig. 2) with no hybridization signal for any satellite DNA family here analyzed. The acrocentric $\mathrm{X}$ chromosome revealed, at least two hybridization signals. In some chromosomes of both species these blocks distributed throughout the chromosomes resemble a banding.

The arrows are indicating the C-bands of each species (from Adega et al., 2007), and were used to ascertain the possible colocalization of the satellite DNA families with the chromosomes constitutive heterochromatin $(\mathrm{CH})$. A high degree of correspondence between these two elements can be directly observed by the co-localization of the C-bands with the satellites hybridization signals. There are nevertheless some few cases where a C-band does not correspond to a specific satellite sequence under analysis and these are marked by an asterisk (*).

\section{Discussion}

The characteristic dynamic rate of the repeats evolution, at the sequence and copy number alteration levels makes these sequences valuable evolutionary markers (Saffery et al., 1999). The molecular analysis of satellite DNA sequences and their physical mapping is a precious tool in measuring species phylogenetic relationships, while also elucidating important aspects of both genome and repetitive sequences evolution (Chaves et al., 2000; Lander et al., 2001; Ugarkovic and Plohl, 2002; Adega et al., 2006a).

Suidae (pigs) and Tayassuidae (peccaries) are supposed to have shared a common ancestor some 40 Mya. The comparison of the pig chromosomal architecture with that of the peccaries by comparative chromosome painting (Bosma et al., 2004; Adega et al., 2006b), revealed around 31-35 different rearrangements necessary for converting each one of the peccaries karyotypes into the pig one. The high diversity of these genomes at the chromosomal organization level, anticipated parallel results for the repetitive fraction of their genomes, namely of the satellite DNA sequences. Using specific primers, we investigated the existence of the two pig (Suidae) major satellite DNA families in the genomes of two species (P. tajacu, PTA and T. pecari, TPE) belonging to Tayassuidae, as well in the pig 
genome, the index Suiformes genome. Interestingly, we were able to isolate pig satellite DNA sequences from the genomes of the two Tayassuidae in analysis, despite its divergence time, moreover, each one of the satellite DNA sequences (AC1SSC, AC1PTA, ACITPE, CE2SSC, CE2PTA and CE2TPE) was successfully hybridized to pig metaphase chromosomes (Fig. 1), and it was possible to analyze their physicaldistribution in the pig genome. The in situ hybridization of the Suidae and related Tayassuidae sequences produced similar hybridization signals in the pig chromosomes, as can be seen in Fig. 1. The positive and very similar signals revealed the homology of these sequences with the ones present in the genome of pig (at least, $82 \%$ homology since the in situ hybridization experiments were performed at $82 \%$ of stringency). TPE sequences seem to be the more diverged from the others, when analyzing the hybridization in the pig chromosomes.

The results revealed to be very enthusiastic, because it is not so common to find a specific satellite DNA family in genomes belonging to families that diverged such a long time ago, as the ones under analysis here. The presence of these sequences in both families genomes gives to these orthologous satellite DNAs, an age of at least, $40 \mathrm{My}$. It is well known that the great majority of the satellite DNA sequences are rapidly evolving (Saffery et al., 1999; Chaves et al., 2005), and this is supported by a vast number of eukaryotic genomes analyzed so far. The finding of these satellites in genomes that radiated so long time ago brings up the question of what occurred to these sequences in this period of time? Our achievements, therefore, contrast with the characteristic dynamic rate of repeats evolution. A high degree of preservation, slow rates of sequence change and of concerted evolution of these satellite DNAs, appears to be a general rule for the pig/peccaries genomes. The most remarkable antiquity found until now for a satellite DNA is that of two ancient satellite DNA families in the genomes of sturgeon species that revealed to be more than 100 My (Robles et al., 2004). Followed by these, the alpha satellite DNA of primates has been recently found to be present also within the genomes of the chicken and zebrafish (Li and Kirby, 2003); a highly homogeneous satellite DNA is also preserved among insect species separated for about $60 \mathrm{My}$, which exhibit absolute sequence conservation (Mravinac et al., 2002), and among plant species of the genus Zamia (Cafasso et al., 2003). These few cases of preservation are indicating a complex behavior of the repetitive genome fraction. Concerted evolution leads to rapid change between repeat sequences of different species, achieved by amplification of new variants during speciation or by gradual sequence evolution due to the accumulation of nucleotide substitutions (Ugarkovic and Plohl, 2002). The changes are established and fixed between species by molecular homogenizing mechanisms, such as amplification, unequal crossing-over, or gene conversion. There are a number of factors that can affect the rate of concerted evolution, as number and arrangement of the repeats and demography. In terms of demography, the time required for a variant to be eliminated or to become fixed in a population clearly depends on the effective population size. The peccaries are confined to a small area of America, ranging from Arizona to Argentina, and two of these species are restricted to some regions of South America, being the various population sizes very limited. This might be one of the factors limiting concerted evolution inside each species to occur, leading to the overall preservation of the satellite families.

Cross-species in situ hybridization (Figs. 2 and 3) was also performed in the peccary's chromosomes in order to ascertain the chromosomal distribution of the satellites in the different genomes, and karyotypes were constructed to better analyze the data (Fig. 2). Curiously, in opposition to the pig, that shows both satellite families located at a specific region-the centromere, the physical investigation of the sequences in the peccaries demonstrated a multiple distribution throughout their genomes, resembling a banding pattern at some chromosomes (Fig. 2). The observed opposing scenarios of the major satellite DNAs physical distribution in the pig (centromeres) versus peccaries (multiple chromosome's locations), confirms and extends our previous knowledge of the high degree of diversity underwent by these genomes after radiation some 40 Mya.

Although related, the Tayassuidae collared and white-lipped peccaries went through an incredible number of rearrangements (23 rearrangements are required to convert one peccary karyotype into the other) (Adega et al., unpublished data). Considering that these karyotypes diverged no more than 2.5-3 Mya (Marshall et al., 1982; Gongora and Moran, 2005), it is easy to recognize the high rate of chromosomal formatting occurred in these species. The comparison of the satellite "banding patterns", with the evolutionary breakpoints of both peccaries with pig paint probes (Bosma et al., 2004; Adega et al., 2006b) revealed its colocalization, that is, the satellite DNA sequences are located at the majority of the evolutionary breakpoints of these species and almost total correspondence was observed between each breakpoint for both species and the presence of a similar amount of satellite DNA on the chromosomes involved (see Fig. 3, where we present, as an example, sintenies between the three species, specifically between PTA3 and PTA5 with TPE4, and SSC6). The satellite DNA assignment to the evolutionary breakpoints is indicative of its implication in the evolutionary rearrangements occurred, besides revealing its previous existence in a common ancestor of the Suidae/Tayassuidae. By parsimony it is highly improbable that these sequences appeared at these locations by convergence, hence, they are orthologous sequences and remnants of the rearrangement events. Constitutive heterochromatin regions are thought to be "hotspots" for structural chromosome rearrangements (Yunis and Yasmineh, 1971; Peacock et al., 1982; John, 1988; Chaves et al., 2004) and satellite DNAs usually resides on CH. Recently, Adega et al. (2007) performed a comparative analysis between $T$. pecari and $P$. tajacu constitutive heterochromatin localization and the breakpoints in each Tayassuidae chromosomes and they observed the co-localization of the $\mathrm{CH}$ with the breakpoints. They thus suggested that the $\mathrm{CH}$ could somehow be involved in the chromosome rearrangements occurred during the evolution of these Tayassuidae species. Here, we assigned almost all satellite DNA locations to $\mathrm{CH}$ bands of both peccaries (Fig. 2). Therefore, the satellite sequences under analysis here might have act as drivers of the occurred rearrangements. The detailed comparison of the peccaries chromosomes after the satellites in situ hybridization (AC1 and CE2) with the $\mathrm{CH}$ regions (Adega et al., 2007) (Fig. 2) reveals, at some locations an apparent lack of correspondence (marked with an asterisk), indicative of the existence of another families of repeated elements in the Tayassuidae karyotypes, namely at the centromeric regions.

The pig major satellite DNA families Mc1 and Ac2 revealed to be preserved in the Suidae/Tayassuidae genomes, for a considerable period of time, exhibiting slow rates of sequence change. In contrast the physical mapping revealed a dynamic motion behavior throughout the peccary's genomes that accompanied the great architectonic reorganization of Tayassuidae chromosomes during evolution. It is not clear whether these satellite sequences are continuing to evolve; the same can be questioned to 
the general chromosomal architecture of Tayassuidae. The recognition of opposite scenarios of satellite DNA versus chromosome architectonic organization observed in the karyotypes of Tayassuidae brings up the fact that chromosomal evolution is an extraordinary and complex multidimensional process.

\section{Acknowledgements}

This work was supported by the project and a PhD grant SFRH/ BD/3280/2000 of the Science and Technology Foundation (FCT) of Portugal, INVOTAN and FCT (SFRH/BSAB/329/2003) sabbatical grants.

\section{References}

Adega, F., Chaves, R., Guedes-Pinto, H., 2006a. Physical organization of the 1.709 satellite IV DNA family in Bovini and Tragelaphini tribes of the Bovidae: sequence and chromosomal evolution. Cytogenet. Genome Res. 114 (2), 140-146.

Adega, F., Chaves, R., Kofler, A., Krausman, P.R., Masabanda, J., Wienberg, J., GuedesPinto, H., 2006b. High-resolution comparative chromosome painting in the Arizona collared peccary (Pecari tajacu, Tayassuidae): a comparison with the karyotype of pig and sheep. Chromosome Res. 14, 243-251.

Adega, F., Chaves, R., Guedes-Pinto, H., 2007. Chromosomal evolution and phylo- genetic analyses in Tayassu pecari and Pecari tajacu (Tayassuidae). Tales from the constitutive heterochromatin. J. Genet. 86 (1), 19-26.

Barry, A.E., Howman, E.V., Cancilla, M.R., Saffery, R., Choo, K.H., 1999. Sequence analysis of an $80 \mathrm{~kb}$ human neocentromere. Hum. Mol. Genet. 8, 217-227. Bosma, A.A., de Haan, N.A., Arkesteijn, G.J., Yang, F., Yerle, M., Zijlstra, C., 2004. Comparative chromosome painting between the domestic pig (Sus scrofa) and two species of peccary, the collared peccary (Tayassu tajacu) and the white- lipped peccary (T. pecari): a phylogenetic perspective. Cytogenet. Genome Res. 105, 115-121.

Cafasso, D., Cozzolino, S., De, L.P., Chinali, G., 2003. An unusual satellite DNA from Zamiapaucijuga (Cycadales) characterised by two different organisations of the repetitive unit in the plant genome. Gene 311, 71-79.

Cawley, S., Bekiranov, S., Ng, H.H., Kapranov, P., Sekinger, E.A., Kampa, D., et al., 2004. Unbiased mapping of transcription factor binding sites along human chromosomes 21 and 22 points to widespread regulation of noncoding RNAs. Cell 116,499-509.

Chaves, R., Guedes-Pinto, H., Heslop-Harrison, J., Schwarzacher, T., 2000. The species and chromosomal distribution of the centromeric alpha-satellite I sequence from sheep in the tribe Caprini and other Bovidae.Cytogenet. Cell Genet.91, 6266.

Chaves, R., Adega, F., Santos, S., Guedes-Pinto, H., Heslop-Harrison, J.S., 2002. In situ hybridization and chromosome banding in mammalian species. Cytogenet. Genome Res. 96, 113-116.

Chaves, R., Adega, F., Heslop-Harrison, J.S., Guedes-Pinto, H., Wienberg, J., 2003. Complex satellite DNA reshuffling in the polymorphic $t(1 ; 29)$ Robertsonian translocation and evolutionarily derived chromosomes in cattle. Chromosome Res. 11, 641-648.

Chaves, R., Santos, S., Guedes-Pinto, H., 2004. Comparative analysis (Hippotragini versus Caprini, Bovidae) of X-chromosome's constitutive heterochromatin by in situ restriction endonuclease digestion: $\mathrm{X}$ chromosome constitutive hetero- chromatin evolution. Genetica 121, 315325.

Chaves, R., Guedes-Pinto, H., Heslop-Harrison, J.S., 2005. Phylogenetic relationships and the primitive $\mathrm{X}$ chromosome inferred from chromosomal and satellite DNA analysis in Bovidae. Proc. Biol. Sci. 272, 2009-2016.

Committee for the Standardized Karyotype of the Domestic Pig, 1988. Standard karyotype of the domestic pig. Hereditas 109, 151-157.

Ekes, C., Csonka, E., Hadlaczky, G., Cserpan, I., 2004. Isolation, cloning and char- acterization of two major satellite DNA families of rabbit (Oryctolagus cunicu- lus). Gene 343, 271-279.

Gongora, J., Moran, C., 2005. Nuclear and mitochondrial evolutionary analyses of collared, white-lipped, and chacoan peccaries (Tayassuidae). Mol. Phylogenet. Evol. 34, 181-189.

Groves, C., Grubb, P., 1993. The suborder suiformes. In: Oliver, W.L.R. (Ed.), Pigs, Peccaries, and Hippos. Status Survey and Conservation Action Plan. Interna- tional Union for Conservation of Nature and Natural Resources, Gland, Switzerland.
Jantsch, M., Hamilton, B., Mayr, B., Schweizer, D., 1990. Meiotic chromosome behaviour reflects levels of sequence divergence in Sus scrofa domesticasatellite DNA. Chromosoma 99, 330-335.

Janzen, M.A., Buoen, L.B., Zhao, F., Louis, C.F., 1999. Characterization of a swine chromosome-specific centromeric higher-order repeat. Mamm. Genome 10,579-584

John, B., 1988. The biology of heterochromatin. In: Verma, R.S. (Ed.), Heterochro- matin: Molecular and Structural Aspects. Cambridge University Press, United States of America.

Kereso, J., Praznovszky, T., Cserpan, I., Fodor, K., Katona, R., Csonka, E., Fatyol K., Hollo, G., Szeles, A., Ross, A.R., Sumner, A.T., Szalay, A.A., Hadlaczky, G., 1996. De novo chromosome formations by large-scale amplification of the centromeric region of mouse chromosomes. Chromosome Res. 4, 226-239.

Kuznetsova, I.S., Prusov, A.N., Enukashvily, N.I., Podgornaya, O.I., 2005. New types of mouse centromeric satellite DNAs. Chromosome Res. 13, 9-25.

Lander, E.S., Linton, L.M., Birren, B., Nusbaum, C., Zody, M.C., Baldwin, J., et al. 2001. Initial sequencing and analysis of the human genome. Nature 409,860 921. Li, Y.X., Kirby, M.L., 2003. Coordinated and conserved expression of alphoid repeat and alphoid repeat-tagged coding sequences. Dev. Dyn. 228, $72-81$.

Marshall, L.G., Butler, R.F., Drake, R.E., Curtis, G.H., 1982. Geochronology of typ Uquian (late Cenozoic) land mammal age, Argentina. Science 216, 986989. Miller, J.R., Hindkjaer, J., Thomsen, P.D., 1993. A chromosomal basis for the differential organization of a porcine centromere-specific repeat. Cytogenet. Cell Genet. 62, 37-41.

Montgomery, G.W., Sise, J.Á., 1990. Extraction of DNA from sheep white blood cells. NZ J. Agric. Res. 33, 437-441.

Mravinac, B., Plohl, M., Mestrovic, N., Ugarkovic, D., 2002. Sequence of PRAT satellite DNA "frozen" in some Coleopteran species. J. Mol. Evol. 54, 774-783.

Peacock, W.J., Dennis, E.S., Gerlach, W.L., 1982. DNA sequence changes and specia-tion. Prog. Clin. Biol. Res. 96, 123-142.

Riquet, J., Mulsant, P., Yerle, M., Cristobal-Gaudy, M.S., Le, T.P., Milan, D., Gellin, J., 1996. Sequence analysis and genetic mapping of porcine chromosome 11 centromeric S0048 marker. Cytogenet. Cell Genet. 74, 127-132.

Robles, F., de la, H.R., Ludwig, A., Ruiz, R.C., Ruiz, R.M., Garrido-Ramos, M.A., 2004 Evolution of ancient satellite DNAs in sturgeon genomes. Gene 338, 133-214.

Rogel-Gaillard, C., Hayes, H., Coullin, P., Chardon, P., Vaiman, M., 1997. Swine centromeric DNA repeats revealed by primed in situ (PRINS) labeling. Cytogenet. Cell Genet. 79, 79-84.

Saffery, R., Earle, E., Irvine, D.V., Kalitsis, P., Choo, K.H., 1999. Conservation of centromere protein in vertebrates. ChromosomeRes. 7, 261-265.

Schwarzacher, T., Heslop-Harrsion, J.S., 2000. Practical in situ Hybridization. Bios, Oxford. Tyler-Smith, C., Willard, H.F., 1993. Mammalian chromosome structure. Curr.Opin. Genet. Dev. 3, 390-397.

Ugarkovic, D., Plohl, M., 2002. Variation in satellite DNA profiles-causes and effects. EMBO J. 21, 5955-5959.

Venter, J.C., Adams, M.D., Myers, E.W., Li, P.W., Mural, R.J., Sutton, G.G., et al., 2001 The sequence of the human genome. Science 291, 1304-1351.

Yunis, J.J., Yasmineh, W.G., 1971. Heterochromatin, satellite DNA, and cell function Structural DNA of eucaryotes may support and protect genes and aid in speciation. Science $174,1200-1209$. 

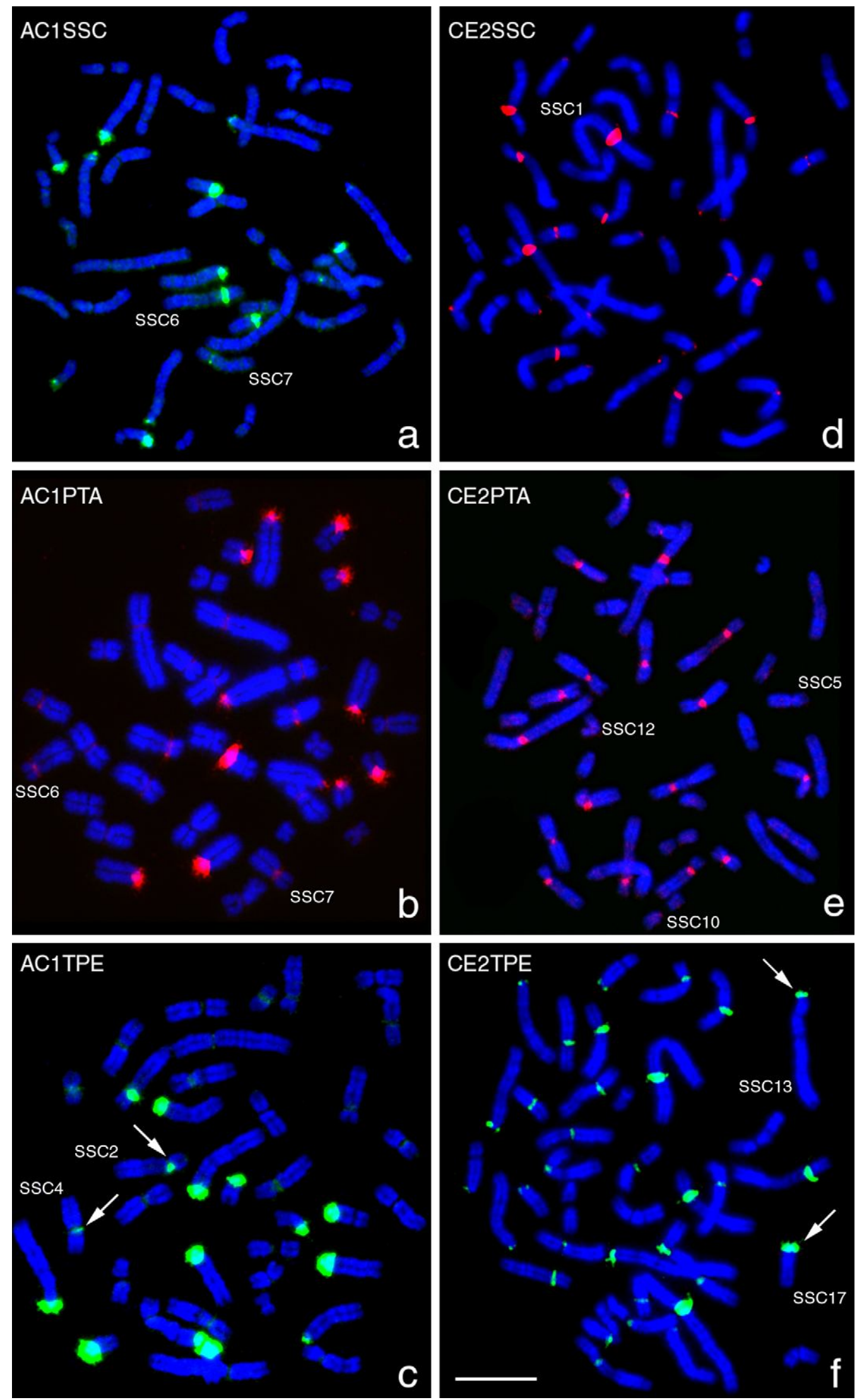

Fig. 1. In situ hybridization of the AC1 and CE2 satellite DNA sequences from Sus scrofa (SSC), Pecari tajacu (PTA) and Tayassupecari (TPE) on SSC chromosomes, specifically: AC1SSC (a), AC1PTA (b), AC1TPE (c), CE2SSC (d), CE2PTA (e) and CE2TPE (f). Scale bar $=8$ mm. 


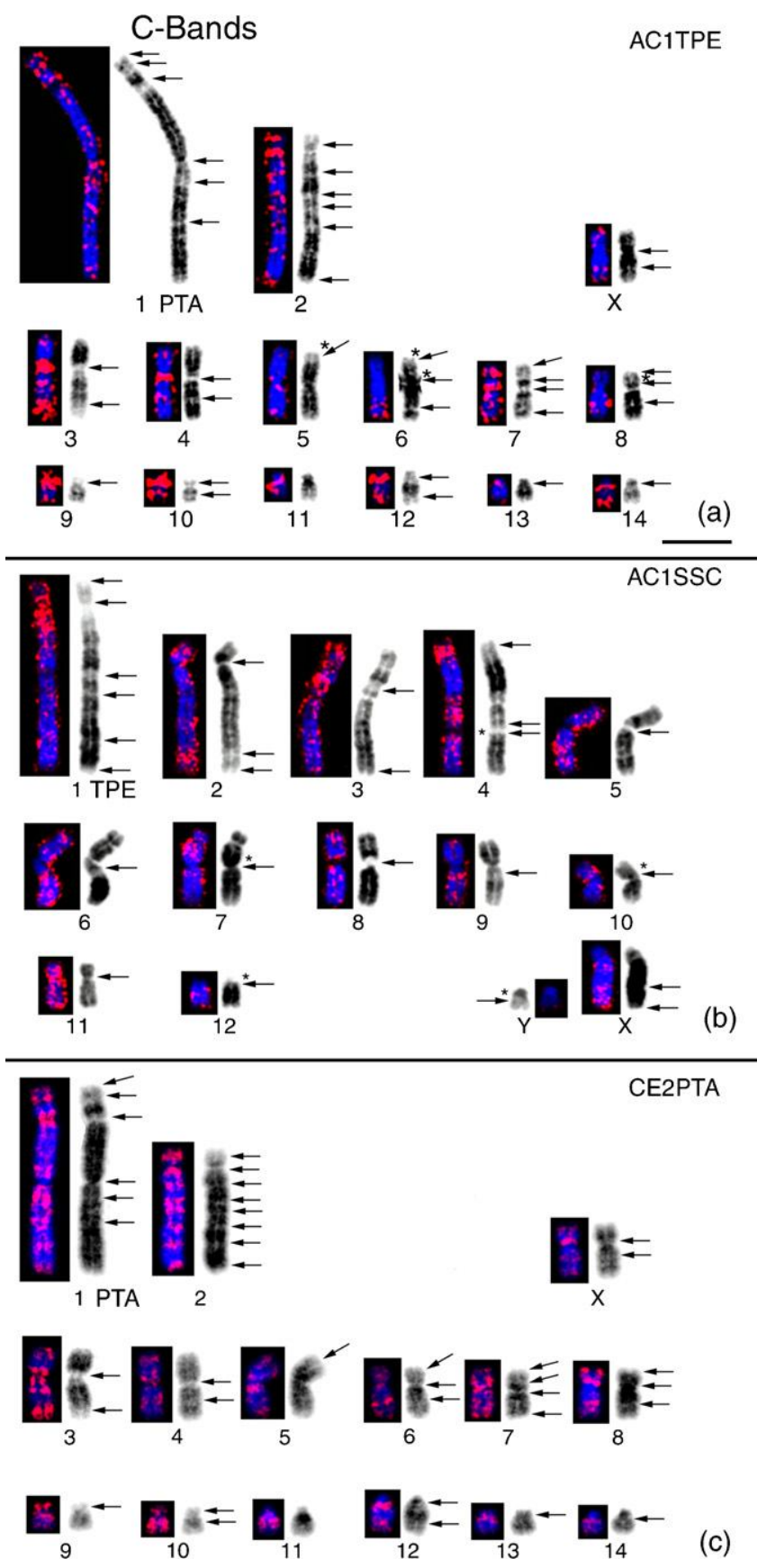

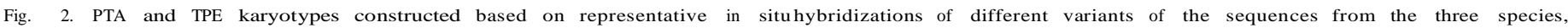

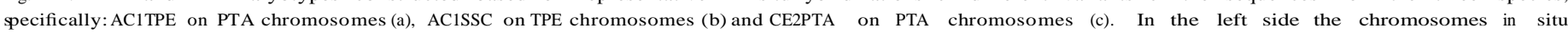

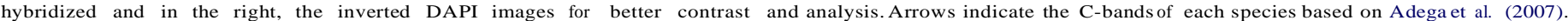
Asterisks $\left(^{*}\right)$ point to some few C-bands with apparent lack of satellite DNAs here in analysis. Scalebar $=8 \mathrm{~mm}$. 


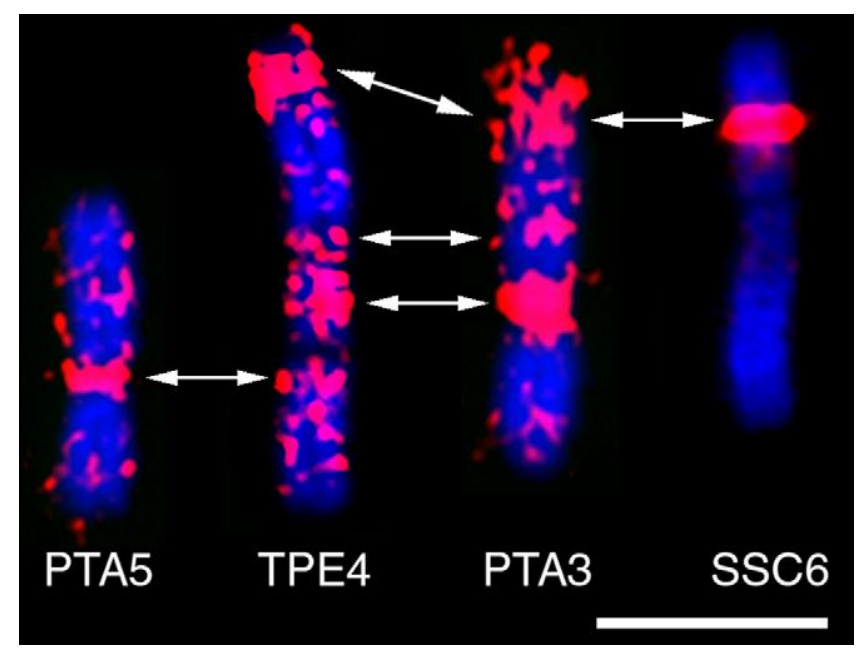

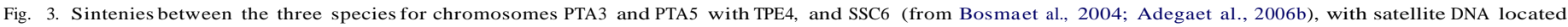

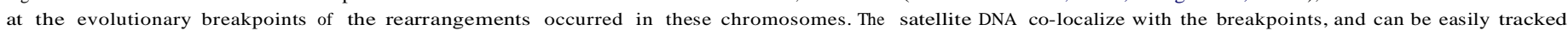
through the three species chromosomes. Scale bar $=5 \mathrm{~mm}$. 